\title{
O USO DAS PASTILHAS DE PARAFORMALDEÍDO POR INSTITUIÇÕES DE SAÚDE DO BRASIL-PARTE II ${ }^{1}$
}

\author{
THE USE OF PARAFORMALDEHYDE TABLETS BY BRAZILIAN HEALTH \\ INSTITUTIONS - PART II
}

\section{EL USO DE LOS PASTILLAS DE PARFORMALDEÍDO POR INSTITUCIONES DE SALUD EN EL BRASIL - PARTE II}

Kazuko Uchikawa Graziano*

Graziano KU. O uso das pastilhas de paraformaldeído por instituições de saúde do Brasil - parte II. Rev Esc Enferm USP 2002; 36(3): 253-61.

\section{RESUMO}

A parte Ido trabalho mostrou que as pastilhas de Paraformaldeido, em condições ambientais, são utilizadas de uma forma muitas vezes inadequada quanto à sua indicação, pela maioria das instituições pesquisadas. Este artigo traz detalhes das formas de utilização das pastilhas de paraformaldeido destacando-se, dentre os problemas, a falta de adesão a uma base teórica que fundamente o processo e a ausência da sua validação, o que compromete a segurança da esterilização. As condições de "esterilização" da maioria das Instituições não incluem temperatura, acréscimo da umidade relativa e não fazem a quantificação adequada das pastilhas, assim como não possuem parâmetros fundamentados que orientem a reutilização de um mesmo grupo de pastilhas de Paraformaldeído nos processos. o uso dos Equipamentos de Proteção Individual (EPI) é bastante valorizado no manuseio deste agente químico.

PALAVRAS-CHAVE: Pastilhas de paraformaldeído. Esterilização química. Desinfecção, Central de Material e Esterilização.

\begin{abstract}
The descriptions of the part I of this study showed that Paraformaldehyde tablets in environmental conditions was used in a brazilian reality as the inadequate choosing way for most of the researched Institutions. This articles shows how this chemical agent is used outstanding problems as the lack of a theoretical base and process validation compromiting, this way, the safety of the sterilization. The "sterilization" conditions of most of the Institutions didn't include temperature, increment of the relative humidity and didn't make the adapted quantification of the tablets. It was observed that the researched Institutions don't have based parameters that guide the reutilization of a same group of Paraformaldehyde tablets in the sterilization processes. The use of Individual Protection Equipment is quite valued in handle of this chemical agent.
\end{abstract}

KEYWORDS: Paraformaldehyde tablets. Chemical sterilization. Higt level of desinfectant activity. Central Supply Unit.

\section{RESUMEN}

Las descripciones de la parte I de este estudio mostrarón que las pastillas de paraformaldeido, en condiciones ambientales, fuerón utilizadas de un forma muchas vezes inadecuada para la mayoria de las instituiciones invetigadas. Este articulo muestra com detalles las formas de utilización de las pastillas de parformaldeido, destacándose problemas como la falta de una base teórica que fundamente el processo o la ausénua de su validación, lo que compromete la seguridad de la esterilización. Las condiciones de la "esterilización de la mayoría de las instituiciones no incluyerón la temperatura, el incremento de la humedad relativa y no realizarón la cuantificación adecuada de las pastillas, assim como no se tienem paramétros fundamentados que puedam orientar la reutilización de un mismo grupo de pastillas de paraformaldeído en los processos de esterilización. El uso de los equipamentos de protección individual (EPI) es bastante valorizado en la manipulación de este agente químico.

PALABRAS-CLAVE: Pastillas de paraformaldeído. Esterilización químico. Desinfección. Central de Materiales e Esterilización.

1 artigo extraído de GRAZIANO, K.U. Avaliação "in vitro" da atividade antimicrobiana das Pastilhas de Paraformaldeïdo, segundo a metodologia da AOAC, reproduzindo as condições de uso nas Instituições de Saúde do Brasil. São Paulo, 1999. 104 p. Tese (Livre Docência) - Escola de Enfermagem, Universidade de São Paulo.

* Enfermeira. Professor Associado do Departamento de Enfermagem Médico-Cirúrgica da Escola de Enfermagem da Universidade de São Paulo (e-mail: rwgraziano@uol.com.br). 


\section{INTRODUÇÃO}

As atividades de pesquisa, ensino e extensão devem estar pautadas em bases concretas. A necessidade de continuar investindo especialmente nas pesquisas sobre a esterilização pelas "superadas" pastilhas de Paraformaldeído, por ser uma realidade nacional, foi demonstrada na parte I do trabalho, onde 253 estabelecimentos de saúde do Brasil (250 hospitais e 3 outros - Centros, Postos e minipostos de Saúde) afirmaram utilizarem-se das pastilhas de Paraformaldeído nos processos de esterilização.

O uso das pastilhas de Paraformaldeído como agente químico esterilizante em condições ambientais, isto é, sem um controle dos parâmetros físicos com auxílio de um equipamento, sempre esteve presente em nosso meio, como a forma mais utilizada nos serviços que adotavam este agente químico.

As condições seguras para a esterilização em condições ambientais utilizando as pastilhas de Paraformaldeído foram pesquisadas por Graziano(1), que seguiu a metodologia da Association of Official Analytical Chemists-AOAC(2) oficialmente adotada pelo Ministério da Saúde do $\mathrm{Brasil}^{(3)}$. Os resultados indicaram a necessidade de uma concentração do agente químico de $3 \%{ }^{(3)} \mathrm{g}$ de pastilhas de Paraformaldeído para cada 100 $\mathrm{cm}{ }^{3}$ do volume do recipiente - em nosso meio, a apresentação comercial das pastilhas é de $0,5 \mathrm{~g} /$ pastilha); temperatura da estufa regulada a $50^{\circ} \mathrm{C}$ (sendo os artigos termossensiveis compativeis com esta temperatura); tempo de exposição de 4 horas (a partir do momento da colocação do material na estufa pré-aquecida àquela temperatura) e umidade relativa de $100 \%$ (obtida com a colocação de um chumaço de algodão molhado com $35 \mathrm{ml}$ de água destilada num recipiente). Sem a garantia da penetrabilidade através dos artigos, mas restrigindose à sua superficie, constatou-se nesse estudo a efetividade da esterilização frente aos esporos do B.subtilis ATCC 19659 e C.sporogenes ATCC 3584 quando penicilindros (carreadores de porcelana dos microrganismos testes) foram contaminados com os microrganismos testes, esporulados, totalizando 480 culturas negativas.

Mesmo após a conclusão dos trabalhos de mestrado (1989) e de doutorado (1995) sobre as pastilhas de Paraformaldeído, e a ampla divulgação dos resultados por meio de publicações em capitulos de livro (45), livretos (6-8), periódicos (9-12) e por meio de comunicações orais em cursos, eventos, palestras, aulas e atendimentos diretos ao público, a observação empirica era de que a antiga forma de utilização, sem uma base teórica que fundamentasse o processo, prevalecia nas Instituições de Saúde.

Em busca das respostas para a questão: "como é realizado o processo de esterilização pelas pastilhas de Paraformaldeído nas instituições do Brasil?" viabilizou-se o presente trabalho com a finalidade de subsidiar um estudo que avaliasse "in vitro" a atividade antimicrobiana das pastilhas de Paraformaldeído reproduzindo as condições de uso naquelas Instituições.

\section{OBJETIVO}

Descrever as diferentes formas de utilização das pastilhas de Paraformaldeído como agente químico esterilizante pelas Instituições de Saúde brasileiras com destaque aos parâmetros: quantidade de pastilhas, tempo de exposição, temperatura, umidade relativa, reutilização das pastilhas e prazo de validade da esterilidade dos artigos processados por este agente.

\section{CASUÍstica E MÉTOdo}

\section{Tipo de pesquisa}

O estudo caracterizou-se como sendo exploratório, descritivo, de campo, transversal com abordagem quantitativa.

\section{População do estudo}

A população alvo deste estudo constituiu-se de todas as Instituições de Saúde do Brasil, cadastradas pelo IBGE/92 (versão mais atualizada na ocasião da coleta de dados) excluindo-se as clínicas particulares e casas de repouso. A população de acesso, que respondeu ao questionário, constituiu-se de 419 hospitais brasileiros e 24 Instituições não exclusivamente hospitalares, como Unidades mistas, Centros, Postos e minipostos de Saúde. Destas, 253 Instituições responderam fazerem uso das pastilhas de Paraformaldeído.

\section{Procedimento de coleta de dados}

Como instrumento de coleta de dados, foi eleito o questionário (ANEXO) contemplando os seguintes aspectos:

- formas de utilização das pastilhas de Paraformaldeído quanto à quantidade e distribuição no recipiente, temperatura, tempo de exposição, umidade relativa, remoção do resíduo do formaldeído do artigo antes do seu uso, controle da certificação da esterilização, período de validade da esterilidade dos artigos processados por este agente químico e sua reutilização; processado;

- observação de dano ou alterações no material

- cuidados relacionados à saúde ocupacional dos funcionários que têm contato com as pastilhas de Paraformaldeído; 
Este questionário foi elaborado a partir de quatro entrevistas realizadas como teste piloto em 1996, junto às enfermeiras responsáveis pela Central de Material e Esterilização dos hospitais no município de São Paulo, que fizeram ou faziam uso das pastilhas de Paraformaldeído como agente químico esterilizante.

O questionário foi acompanhado por uma carta de apresentação dirigida à enfermeira da Divisão de Enfermagem, com a solicitação da resposta do questionário, num prazo de 15 dias (ANEXO). O retorno dos questionários respondidos foi considerado como os sujeitos da pesquisa terem consentido em participar do mesmo de uma forma livre e esclarecida.

O período da coleta de dados foi de setembro de 1997 a janeiro de 1999, sendo que o envio dos questionários encerrou-se em novembro de 1998.

As respostas recebidas após 31/01/1999 não foram consideradas na tabulação dos dados do presente estudo.

A ordem dos Estados brasileiros a serem contatados foi definida por meio de sorteio.

As respostas dos questionários foram organizadas e sintetizadas em forma de Tabelas por meio de números absolutos e percentuais.

\section{RESULTADOS}

Da amostra das Instituições de Saúde do Brasil que fazem uso das pastilhas de Paraformaldeído, a quantidade de pastilhas de Paraformaldeído utilizada é apresentada na Tabela 1:

Tabela 1 - Distribuição das freqüências das Instituições de Saúde dos Estados Brasileiros quanto à quantidade de pastilhas de Paraformaldeído utilizadas no processo de esterilização. São Paulo, 1997/1999.

\section{QUANTIDADE DE PASTILHAS $\mathbf{N}^{\circ} \%$ UTILIZADAS}

\begin{tabular}{|c|c|c|}
\hline & & \\
\hline Variável e aleatória & 81 & 50,6 \\
\hline $\begin{array}{l}3 \% \\
\text { F } \\
\text { semnre ioylal indenendente do volume }\end{array}$ & 33 & 20.6 \\
\hline $\begin{array}{l}\text { H. semnre 19ual. indenendente do voliume } \\
\text { recibiente }\end{array}$ & 04 & 2.50 \\
\hline 5 nastilhas $/ 100 \mathrm{~cm} 2$ (foi imnossivel o & 04 & 2.50 \\
\hline 3 gramas de nastilha / $\mathrm{cm} 3(150 \% *)$ & 0 & .8 \\
\hline 5 gramas de nastilha / $100 \mathrm{~cm} 3(5 \% *)$ & 04 & .50 \\
\hline 5 nastilhas $/ 100 \mathrm{~cm} 3 / 2.5 \% * 1$ & 02 & 2.5 \\
\hline 10 nastilhas $/ \mathrm{m} 3(0.0005 \% *)$ & 02 & 1.25 \\
\hline 1 pastilha / cm3 (50\%*) & 13 & \\
\hline Outros & & \\
\hline TOTAL & 160 & 100 \\
\hline
\end{tabular}

* Os cálculos da porcentagem foram feitos considerando-se a massa de $0,5 \mathrm{~g}$ por pastilha.

"93 instituições (36,75\%) não responderam a esta questão. (117) da população pesquisada, Paraformaldeído, somente $25,69 \%$ dos Estabelecimento uma vez que as pastilhas mantêm-se aparentemente de Saúde pesquisados afirmaram positivamente, sendo integras, mesmo após várias reutilizações. Dos
$60,00 \%$ por meio de algodão úmido com água destilada, $4,61 \%$ com água destilada em um recipiente e outras formas não explicitadas 35,38\%.

Quanto à utilização do aquecimento durante o processo de esterilização com as pastilhas de Paraformaldeído, 43,42\% das Instituições pesquisada utilizam-se do aquecimento durante o processo de esterilização, sendo a temperatura diversa, conforme mostra a Tabela 2:

Tabela 2 - Distribuição das freqüências das Instituições de Saúde dos Estados Brasileiros quanto às temperaturas usadas no aquecimento dos artigos durante o processo de esterilização por meio das pastilhas de Paraformaldeído. São Paulo, 1997/ 1999.

\begin{tabular}{|c|c|c|}
\hline TEMPERATURAS & $\mathbf{N}^{\circ}$ & $\%$ \\
\hline $50^{\circ} \mathrm{C}$ & 42 & 38,53 \\
\hline $60^{\circ} \mathrm{C}$ & 18 & 16,51 \\
\hline $80^{\circ} \mathrm{C}$ & 07 & 2,76 \\
\hline $100^{\circ} \mathrm{C}$ & 07 & 2,76 \\
\hline Outras & 23 & 9,09 \\
\hline Não especificou & 12 & 4,74 \\
\hline TOTAL & $109 *$ & 100,00 \\
\hline
\end{tabular}

144 (56,58\%) Instituições não se utilizam do aquecimento durante o processo de esterilização.

A Tabela 3 apresenta os períodos de exposição dos artigos médico-hospitalares submetidos às pastilhas de Paraformaldeído nas instituições de saúde

Tabela 3 - Distribuição das freqüências das Instituições de Saúde dos Estados Brasileiros quanto aos períodos de exposição dos artigos críticos médicohospitalares submetidos às pastilhas de Paraformaldeído. São Paulo, 1997/ 1999.

\begin{tabular}{lrr}
\hline $\begin{array}{l}\text { PERÍODO DE EXPOSIÇÃo DOS } \\
\text { ARTIGOS ÀS PASTILHAS DE } \\
\quad \text { PARAPORMALDEİDO }\end{array}$ & $\mathbf{N}^{\circ}$ & $\%$ \\
\hline 1 hora & 13 & 5,23 \\
2 horas & 8 & 3,22 \\
3 horas & 5 & 2,01 \\
4 horas & 32 & 12,86 \\
5 horas & 29 & 11,65 \\
12 horas & 30 & 12,01 \\
24 horas & 54 & 21,69 \\
Até o próximo uso & 43 & 17,27 \\
Outros & 35 & 14,06 \\
\hline TOTAL & \multicolumn{3}{c}{$249 *$} & 100,0 \\
\hline (1,58\%) Instituições não responderam a esta questão.
\end{tabular}

A reutilização do mesmo grupo de pastilhas de Paraformaldeído nos processos de esterilização por integras, mesmo após várias reutilizaçoes. Dos pesquisadas. 
Estabelecimentos de Saúde que reutilizam o mesmo grupo de pastilhas de Paraformaldeído, o número de reutilizações está apresentado na Tabela 4:

Tabela 4 - Distribuição das freqüências das Instituições de Saúde dos Estados Brasileiros quanto ao número de reutilizações das pastilhas de Paraformaldeído no processo de esterilização. São Paulo, 1997/1999.

\begin{tabular}{lcc}
\hline \multicolumn{1}{c}{ N Ú MERO DE } & N $\mathbf{N}^{\circ}$ & $\%$ \\
\hline 2 vezes & 13 & 10,83 \\
3 vezes & 9 & 7,50 \\
4 vezes & 6 & 5,00 \\
12 vezes & 6 & 5,00 \\
Até diminuírem de tamanho & 5 & 4,17 \\
Até desaparecerem & 27 & 22,50 \\
Enquanto houver odor & 2 & 1,67 \\
caracteristico & 49 & 40,83 \\
Outros & $117^{*}$ & 100,0 \\
\hline TOTAL
\end{tabular}

- 133 (52,57) Instituições não reutilizam o mesmo grupo de pastilhas de Paraformaldeído e $3(2,50 \%)$ não responderam a esta questão.

Quanto aos dados referentes ao contato do gás formaldeído sublimado das pastilhas de Paraformaldeído como agente químico esterilizante, com o artigo a ser processado as respostas são apresentadas na Tabela 5.

Tabela 5 - Distribuição das freqüências das Instituições de Saúde dos Estados Brasileiros quanto às formas de contato das pastilhas de Paraformaldeído com os artigos médico-hospitalares nas Instituições de Saúde brasileiras. São Paulo, 1997/1999.

\begin{tabular}{lcc}
\hline \multicolumn{1}{c}{ CONTATO DAS PASTILHAS } & $\mathbf{N}^{\circ}$ & $\%$ \\
COM OS ARTIGOS & & \\
\hline As pastilhas não ficam em contato & 175 & 70,00 \\
Pastilhas envoltas em gaze & 47 & 18.80 \\
Pastilhas são cobertas com tecido & 5 & 2.00 \\
Pastilhas são colocadas em & 4 & 1,60 \\
Pastilhas cobertas com compressa & 2 & 0.80 \\
Pastilhas envoltas em alondão & 2 & 0.80 \\
Pastilhas colocadas em envelone de & 1 & 0.40 \\
Não é utilizada aualauer embalagem & 10 & 4.00 \\
Não respondeu & 7 & 1,60 \\
\hline TOTAL & 253 & 100,0 \\
\hline
\end{tabular}

O armazenamento dos artigos esterilizados é uma prática nas Centrais de Materiais, para que possam atender à demanda das unidades consumidoras. Em relação aos artigos processados pelo Paraformaldeído, a informação sobre o prazo de validade da esterilidade atribuído a estes artigos está apresentada na Tabela 6:
Tabela 6 - Distribuição das freqüências das Instituições de Saúde dos Estados Brasileiros quanto ao prazo de validade da esterilidade atribuído ao artigo processado pelas pastilhas de Paraformaldeído. São Paulo, 1997/1999.

\begin{tabular}{lrr}
\multicolumn{1}{c}{$\begin{array}{c}\text { PRAZO DE VALIDADE DA } \\
\text { ESTERILIZAÇÃO }\end{array}$} & $\mathbf{N}^{\circ}$ & \% \\
\hline Sem prazo de validade & 26 & 16,04 \\
Até desaparecerem as pastilhas & 02 & 1,23 \\
7 dias & 36 & 22,22 \\
15 dias & 30 & 18,51 \\
30 dias & 19 & 11,72 \\
Outros & 49 & 30,24 \\
\hline TOTAL & $162 *$ & 100,0 \\
\hline
\end{tabular}

*91 (35,96\%) Instituições não responderam a esta questão.

Sabe-se que o gás formaldeído polimeriza-se sobre as superficies dos artigos, podendo formar uma fina película residual do paraformaldeído. O cuidado na remoção de resíduos é inerente a todos os processamentos de artigos, por qualquer agente químico. Do universo total de respostas aos questionários apenas 35,22\% fazem tratamento dos artigos antes da sua utilização sendo a remoção do resíduo de Paraformaldeído feito com soro fisiológico em 86,20\%; com álcool a 70\% em 2,29\%; por meio de compressa úmida em 3,34\%; com água corrente em $3,44 \%$ e por outras formas não especificadas 2,29\%.

É frequente o relato de danos observados nos artigos que foram processados pelas pastilhas de Paraformaldeido, especialmente naqueles com componentes metálicos. A maioria respondeu negativamente $(81,20 \%)$ à observação de danos sobre os artigos processados.

A certificação dos processos de esterilização é uma preocupação de todos que respondem pela segurança do reprocessamento de artigos médicohospitalares. Em relação a este aspecto, somente 7,60\% gerenciam este controle, sendo que 57,89\% fazendo cultura microbiológica de uma amostra de material processado pelas pastilhas de Paraformaldeído; 1,58\% com testes biológicos sem a citação do microrganismo teste; $0,79 \%$ utilizando o B.subtilis e $0,79 \%$ por outros meios não explicitados.

Felizmente, a saúde ocupacional é um aspecto que vem sendo cada vez mais enfocado nas nossas práticas diárias. Conforme já foi discutido o formaldeído não é desprovido de toxicidade. Dos Estabelecimentos de Saúde pesquisados 73,57\% que utilizam pastilhas de Paraformaldeído citaram o uso de Equipamentos de Proteção Individual (EPI) como cuidado no manuseio das mesmas. 


\section{DISCUSSÃO}

A triade temperatura, concentração do gás esterilizante e tempo de exposição são variáveis fisicas que interferem diretamente nos processos de esterilização gasosa.

Pelas próprias características do gás formaldeído, que necessita de calor e umidade para garantir o efeito microbicida (13-15) é um risco desconsiderar estas premissas ao utilizar-se as pastilhas de Paraformaldeído para a esterilização em condições ambientais (sem aquecimento em $56,58 \%$ da população estudada, segundo os dados da Tabela 2 .e sem umidade adicional em 74,30\%) . A maioria dos questionários respondidos indicaram periodos longos de exposição como $24 \mathrm{~h}$, porém, houve Instituições de Saúde que citaram períodos curtos de exposição como 1h $(5,23 \%)$, $2 \mathrm{~h}(3,22 \%)$, $3 \mathrm{~h}(2,01 \%)$, conforme os dados da Tabela 3. Quando as bactérias são expostas a um agente bactericida numa concentração específica, mesmo em excesso, nem todos os microrganismos morrem ao mesmo tempo, mas ocorre uma diminuição gradual do número de células vivas, sendo o tempo de exposição um fator importante (16). A revisão da literatura sobre as formas de utilização do Paraformaldeído como agente esterilizante em condições ambientais (sem o uso de equipamento específico), indica que não existe um consenso entre os vários autores, o que pode ser atribuído à diversidade de metodologias de análises empregadas. Sabe-se que não há, até o momento, uma metodologia oficial de avaliação de agentes químicos

antimicrobianos, aceita universalmente (17). Os Estados Unidos foram os pioneiros na padronização de métodos, seguidos pelo Reino Unido, Alemanha, Holanda e França. Em alguns países foram estabelecidas as definições e os critérios, mas os testes não foram propostos. Em 1985, o Ministério da Saúde do Brasil, conforme já foi comentado na introdução deste trabalho, adotou como metodologia oficial de análise para a aprovação dos agentes químicos esterilizantes, a dos Estados Unidos, que segue a preconizada pela AOAC (2). Assim, os diferentes autores estabelecem parâmetros divergentes para a esterilização de superficie dos artigos, por meio das pastilhas de Paraformaldeído utilizando diversos métodos de análise, como o de Salzano(18) que concluiu que o paraformaldeído, quando colocado na estufa a $50^{\circ} \mathrm{C}$, por um período de exposição de duas horas e numa concentração de $5 \%$, esteriliza o material cirúrgico previamente limpo e seco; Schilling B, Wigert H, Weuffen W, Dobeberkau HJ.(19) que chegaram à conclusão que a esterilização de materiais requer dez tabletes por $\mathrm{dm}^{3}$ do volume do recipiente, com tempo de exposição de quinze a vinte e quatro horas, sem submeter os materiais ao aquecimento além da temperatura ambiente, com umidade relativa de $80 \%$; Martindale ${ }^{(20)}$ que faz referências sobre a ação esterilizante do paraformaldeído a $0,1 \%$ e $0,15 \%$ à temperatura de $16^{\circ} \mathrm{C}$, cobrindo o recipiente com uma camada de gaze levemente úmida e Cunha, Almeida, Mimica (21) que estudaram a ação microbicida do paraformaldeído a $1 \%$ à temperatura ambiente e mostraram que, após oito horas de exposição o material encontrava-se esterilizado.

As condições de esterilização utilizando as pastilhas de Paraformaldeído, segundo a pesquisa de Graziano (1), seguindo a metodologia da AOAC, oficialmente adotada pelo Ministério da Saúde do Brasil (3', indicaram: concentração de $3 \%$; temperatura de $50^{\circ} \mathrm{C}$; tempo de exposição de 4 horas e umidade relativa de $100 \%$.

Analisando as diversas formas de utilização das pastilhas de Paraformaldeído para a esterilização de artigos nas Instituições Hospitalares pesquisadas, nota-se não só a diversidade do uso mas também a falta de adoção de bases teóricas que fundamentem o processo.

Quanto à reutilização das pastilhas de Paraformaldeído, os resultados do levantamento mostraram que poucas enfermeiras adotam critérios norteadores, conforme mostra a Tabela 4. No trabalho de Graziano (22) foi demonstrado que as pastilhas de Paraformaldeído mantêm ação esterilizante em até 12 ciclos de reutilização quando processadas a $3 \%, 50^{\circ} \mathrm{C}$ por $4 \mathrm{~h}$ sob umidade relativa máxima. Respostas como "......reutilizo até as pastilhas desaparecerem..."; " ........ reutilizo enquanto as pastilhas exalam odor característico" mostram a prática empírica presente nas ações do enfermeiro.

A ausência de danos observados nos artigos processados pelas pastilhas de Paraformaldeído ( $81,20 \%$ ) vêm ao encontro às observações da autora. Desde 1992, quando concluiu os experimentos dos trabalhos de Doutorado, as pastilhas de Paraformaldeído permaneceram em 12 recipientes fechados de alumínio. Após 7 anos, estes recipientes foram abertos, sem a constatação de qualquer ação corrosiva sobre o alumínio. As pastilhas estavam conservadas quanto à forma e exalando ainda o odor característico. A oxidação do material processado pelas pastilhas de Paraformaldeído, relatada pelas usuárias, pode ser atribuída mais à umidade utilizada no processo e menos à ação corrosiva do princípio ativo. A descrição da literatura das características físicoquímicas do formaldeído não ressalta a sua ação oxidante sobre matérias primas como alumínio, inox e plásticos. Os alertas destacados no uso do formaldeído gasoso enfoca o aspecto da toxicidade decorrente à absorção e adsorção do gás nas matérias primas como papelão, látex e têxteis (23-26).

Outro fator que pode contribuir para a oxidação do material, especialmente das furadeiras de uso doméstico adaptadas para uso em cirurgias, é a qualidade da sua matéria prima. Ao desviar-se da 
finalidade para a qual são fabricados, os equipamentos não observância deste detalhe faz com que quantidades não resistem às agressões fisicas e químicas inerentes de germicida sejam carreadas para os meios de cultura aos processos de esterilização.

A aleatoriedade no cálculo da quantidade de pastilhas de Paraformaldeído usadas nas Instituições de Saúde pesquisadas compromete a segurança do processo. Mantendo as outras condições constantes, com poucas exceções, o aumento da concentração do princípio ativo do germicida aumenta a eficácia e diminui o tempo necessário para a morte microbiana (27).

fazendo com que os usuários cheguem a falsas conclusões quanto à segurança de esterilização.

$\mathrm{Na}$ escolha de um indicador biológico para certificar a efetividade de um processo de esterilização, o critério norteador deve ser a sua especial resistência a esse processo, assegurando a característica de baixa patogenicidade do microrganismo ao homem. O

Um fator complicador no uso das pastilhas de indicador biológico de eleição devido à sua reconhecida Paraformaldeído é a utilização da unidade dm' para resistência ao agente químico formaldeído. As duas cálculo das pastilhas, proporcional ao volume do únicas Instituições de Saúde que fizeram referência recipiente por algumas Instituições de Saúde (Tabela 1), ao indicador biológico para a certificação do processo uma vez que esta unidade de medida não é usual no citaram o Bacillus subtilis.

nosso meio, exigindo-se cálculos de conversão para $\mathrm{cm}^{3}$.

A validação microbiológica do processo de

O procedimento seguro de esterilização esterilização utilizando o formaldeído gasoso nas utilizando as pastilhas de Paraformaldeído deverá condições ambientais tem um fator complicador uma obedecer ao cálculo do volume interno do recipiente vez que devem ser utilizados Indicadores biológicos onde o artigo será esterilizado, com a quantificação de primeira geração, que necessitam da infra-estrutura correspondente do número necessário de pastilhas, dos laboratórios de microbiologia para o seu cultivo. colocando-as espalhadas no fundo do recipiente. O O teste biológico pode ser feito com o Bacillus artigo a ser processado, previamente limpo, deverá stearotermophilus impregnado num disco de papel ser separado das pastilhas com um máximo de três de filtro como monitor biológico, numa quantidade de camadas de gazes abertas. A caixa deverá ser lacrada inóculo de $10^{5}$ a $10^{6}$ e após a exposição ao processo, com fita crepe e identificada. Deve-se expor os artigos semeado num meio de cultura com neutralizante pelo tempo e temperatura indicados, podendo-se tiossulfito de sódio a $0,1 \%$.

armazená-los ou utilizá-los imediatamente após o processo.

O fato dos enfermeiros não adotarem

Destaca-se a necessidade da remoção dos referenciais teóricos para o uso das pastilhas de Paraformaldeído reforça a idéia de uma prática cultural resíduos de formaldeído depositados nas superficies da profissão ainda pautada nas tradições, rotinas e dos artigos, antes da utilização destes, com compressa experiências. A escolha dos processos de esterilização estéril úmida em soro fisiológico ou água destilada não pode mais estar à mercê de pedidos particulares estéril, utilizando técnica asséptica.

Em algumas Instituições de Saúde pesquisadas, várias formas inadequadas de contato do gás formaldeído sublimado das pastilhas de Paraformaldeído com o artigo a ser processado foram constatas como "pastilhas cobertas por tecido", "pastilhas colocadas em
embalagens plásticas ou em envelopes de papel", inviabilizando o contato do agente químico com os artigos a serem processados (Tabela 5).

A maioria das Instituições de Saúde pesquisadas $(57,80 \%)$ fundamenta o processo de esterilização utilizando o gás formaldeído em resultados de culturas microbiológicas negativas. O formaldeído gasoso, após resfriamento, polimeriza-se sobre as superficies dos artigos processados, deixando uma fina camada de resíduo responsável pela ação bacteriostática em qualquer cultura de prova de esterilidade. Para contornar os resultados falso-negativos nas culturas de prova, a AOAC (2) e outros autores ${ }^{(17,28-30)}$ dos usuários, que muitas vezes priorizam a conservação do instrumental ao invés da segurança do processo. Nessas circunstâncias, o que normalmente é apresentado como justificativa é que os pacientes assim operados não apresentaram processos infecciosos, porém, desconsideram que a infecção hospitalar é multicausal e o paciente evoluir ou não com infecção, não pode ser o parâmetro para validar um processo de esterilização. A infecção é sempre um resultado do confronto entre a agressão microbiana e a resistência do hospedeiro.

Os efeitos tóxicos e de caráter eminentemente irritativo do gás formaldeído devem ser valorizados com o uso de equipamentos de proteção individual (EPI), minimamente luvas, máscaras e óculos de proteção, juntamente com os cuidados de rodízio dos trabalhadores do setor e uso de exaustores adequados do ambiente onde o processo é realizado. Os resultados da pesquisa mostraram que a maioria das Instituições recomendam a neutralização como uma etapa de Saúde $(71,95 \%)$ fazem uso de EPI no manuseio fundamental, sendo $0,1 \%$ de tiossulfito de sódio o das pastilhas de Paraformaldeído. A avaliação neutralizante recomendado pela AOAC (2) no meio de toxicológica é de maior importância, pois a toxicidade cultura onde a prova de esterilidade é realizada. A também afeta na escolha do produto (31). O formaldeído, 
além de queratinizar e sensibilizar a pele por contato, pode provocar a irritação das mucosas respiratória e ocular, causar a asma, bronquite, pneumonite e outros problemas de vias respiratórias. O teor máximo permitido no ar é de 1 ppm(23).

A precaução recomendada para a remoção do resíduo do agente químico no material por ele processado é enxaguá-lo assepticamente em água esterilizada antes do uso(32). Porém, na impossibilidade deste procedimento, aconselha-se a remoção do resíduo utilizando uma compressa úmida com água destilada estéril ou soro fisiológico. No presente estudo, constatou-se que a maioria $(64,78 \%)$ não remove o resíduo tóxico das pastilhas de Paraformaldeido dos artigos, antes da sua utilização.

Quanto às questões referentes ao período de validade da esterilidade dos artigos submetidos a esse processo, a maioria das usuários estipulou um prazo de sete a quinze dias, conforme dados da Tabela 6. Considerando-se que os recipientes de aluminio lacrados são embalagens ideais por serem impermeáveis e como o período de validade da esterilidade está prioritariamente atrelado às características desta embalagem, pode-se afirmar que enquanto estes recipientes não forem abertos, o material pode ser considerado estéril. Estas ponderações foram observadas em 16,04\% das respostas dos questionários. Convém ressaltar que quanto mais longa a permanência dos artigos em componentes metálicos com a umidade residual do recipiente, tanto maior será a probabilidade de corrosão.

\section{CONCLUSÕES}

O presente estudo permitiu chegar às seguintes conclusões:

- as pastilhas de Paraformaldeído, em condições ambientais, são utilizadas de uma forma diversificada e inadequada nas Instituições de Saúde pesquisadas, destacando-se dentre os problemas, a falta de adesão a uma base teórica que fundamente o processo e a ausência de sua validação, o que compromete a segurança da esterilização. As condições de "esterilização" da maioria das Instituições não incluem temperatura, acréscimo da umidade relativa e não fazem a quantificação adequada das pastilhas, assim como não possuem parâmetros fundamentados que orientem a reutilização de um mesmo grupo de pastilhas de Paraformaldeído nos processos.

- a maioria das Instituicoões de Saúde contatadas e que responderam às questões propostas (71,95\%) afirmaram utilizar Equipamento de Proteção Individual (EPI) no manuseio das pastilhas de Paraformaldeído.

\section{REFERÊNCIAS BIBLIOGRÁFICAS}

(1)Graziano KU. Avaliação da atividade esterilizante do paraformaldeído. [dissertação] São Paulo (SP): Escola de Enfermagem da USP; 1989.

(2)Association of official analytical chemists. Official method of anlysis of the Association of Official Analytical Chemists. 15.ed. Washington; 1995. p.65-77: Desinfectants.

(3)Brasil. Leis etc. Portaria n. 67 de 21 de fevereiro de 1985. Dispõe sobre "Normas complementares específicas para registro de saneantes domissanitários com ação antimicrobiana. Diário Oficial da União, Brasília, 27 fev. 1985. Seção 1, p.3180-4.

(4)Lacerda RA, Peniche ACG, Silva A, Bianchi ERF, Graziano KU, Gatto MAF, Avelar MCQ., Jouclas VMG. Buscando compreender a infecção hospitalar no paciente cirúrgico. São Paulo: Atheneu; 1992.

(5)Graziano KU, Silva A, Bianchi ERF. Métodos de proteção anti-infecciosa. In: Fernandes AT. Infecção hospitalar e suas interfaces na área da saúde. São Paulo: Atheneu; 2000.p. 266-308.

(6)Padoveze MC, Monte MCCD (coords.),GrazianoKU et al. Esterilização de artigos em Unidades de Saúde. São Paulo: Associação Paulista de Estudos e Controle de Infecção Hospitalar -APECIH; 1998.

(7)Recomendações práticas em processos de esterilização em estabelecimento de saúde, parteI: esterilização a calor. Campinas: Komedi; 2000.

(8)Práticas recomendadas da SOBECC. São Paulo: SOBECC; 2000

(9)Graziano KU, Cianciarullo TI, Gontijo Filho PP. Avaliação da atividade esterilizante do paraformaldeído. Rev Bras Enf 1989; 42:79-89.

(10)Graziano KU, Cianciarullo TI, Gontijo Filho PP. Avaliação da atividade esterilizante do paraformaldeído. Rev Microbiol 1990; 21:167-9.

(11)Graziano KU, Cianciarullo TI, Gontijo Filho PP Avaliação da atividade esterilizante do paraformaldeído. Rev Esc Enf USP 1991; 83:94.

(12)Graziano KU. Evaluation of sterilizing activity of Paraformaldehyde tablets. In: Anais do $\mathrm{X}$ World Conference of Operating Room Nurses; 1997 set. 368-81; Toronto: Association Operating Room Nurses; 1997. p. 368-81.

(13)Hoffman RK, Spiner DR. Effect of relative humidity on the penetrability and sporicidal activity of formaldehyde. Appl. Microbiol 1970; 20:616-9.

(14)Newson SWB, Matheus J. Use and methods for testinfg formaldehyde sterilization. In: Collins $\mathrm{CH}$, Allwood MC, Bloomfield SF, Fox A. Desinfectants: their use and evaluation of effectiveness. London: Academic Press; 1981. p.61-76.

(15)Mecke P. Desinfection and sterization of thermolabile instruments with gaseous formaldehyde. Zbl Bakteriol Mikrobiol Hyg (B) 1984; 179: 529-43. 
(16)Joklik WK, Willet HP, Amos DB. Zinsser microbiology. 18.ed. Norwalk: Appleton-Century-Crofts; 1984. p. 233-49.

(17)Crémieux A, Fleurette J. Methods of testing desinfectants. In: Block SS. Desinfection, sterilization and preservation. 3 ed. Philadelphia: Lea \& Febiger; 1983. cap. 46, p. 918-45.

(18) Salzano SDT. Estudo sobre a ação do parafórmico nas bactérias em forma esporulada. Rev Esc Enf USP 1968; 2:4657.

(19) Shilling B, Wigert H, Weuffen W, Dobeberkau HJ. Use of paraformaldehyde tablets for bacterial count redution desinfection, cold sterilization and sterile preservation of medical instruments. Pharmazie 1982; 37:518-21.

(20)Martindale W. The extra farmacopeia. 29.ed. London: The Pharmacentical Press; 1972. p. 961-2.

(2 1) Cunha MC, Almeida GV, Mimica IM. Uso do paraformaldeído como método de esterilização. Arq Bras Oftal 1988; 5:178-80

(22)Graziano KU. Reutilização das Pastilhas de Paraformaldeído: avaliação da sua atividade esterilizante. [tese] São Paulo (SP): Escola de Enfermagem da USP; 1995.

(23)Casarett $L J$, Doull J. Toxicology: the basic science of poisons. 3.ed. New York: Mac Millan; 1986.

(24)Feltre R. Química. 2 ed. São Paulo: Moderna; 1982. v. 1.
(25)Fire prevention information and publications centre. Paraformaldehyde. Fire Prey 1978; 126:45-6.

(26)Formaldehyde. The safety practitioner 1985; 3:12-3.

(27)Rutala WA. Disinfection, sterilization and waste disposal. In: Wenzel RP. Prevention and control of nosocomial infections. Baltimore: Williams \& Wilkins; 1987. cap. 18, p. $257-345$.

(28)Roessler WG. Safety evaluation of antimicrobial chemicals. In: Block SS. Desinfection, sterilization and preservation. 2. ed. Philadelphia: Lea \& Febiger; 1977. p. 152-66.

(29)Reiybrook G. The evaluation of the antimicrobial activity of desinfectants. In: Russel, A.D.; Hugo, W.B.; Ayliffe, G.A.J. Principles and practice of dessinfection preservation and sterilization. London: Blackwell Scientific Publications; 1982. cap.4, p.134-57.

(30)Russel AD. Neutralization procedine in the evaluation of bactericidal activity. In: Collins $\mathrm{CH}$, Alwood $\mathrm{MC}$, Bloomfield F, Fox A. Desinfectants: their use and evaluation of effectiveness. London: Academic Press; 1981. p.207-45.

(31)Rutala, WA. APIC guideline for selection and use of disinfectants. Am J Infect Control 1990;18: 99-117.

(32)Collins CH, Allwood MC, Bloomfield SF, Fox A. Desinfectants: their use and evaluation of effectiveness. London: Academic Press; 1981.

\section{ANEXO}

São Paulo, data/ mês/ ano

À Diretora do Serviço de Enfermagem.

Prezada Senhora,

Gostaríamos de contar com a sua preciosa colaboração para a realização da pesquisa intitulada "Estudo do uso das pastilhas de Paraformaldeído em Instituições Hospitalares".

Para tanto, solicitamos que o questionário em anexo seja respondido pela enfermeira responsável pelos setores onde as pastilhas de Paraformaldeído são utilizadas.

Solicitamos que as respostas sejam devolvidas o mais rápido possivel num prazo máximo de 15 dias, endereçada à Escola de Enfermagem da USP, Av. Dr. Enéas Carvalho Aguiar, 419 Cerqueira César, São PauloSP, CEP 05403-000, aos cuidados de Kazuko Uchikawa Graziano, no Depto. ENC sala 324. Será assegurado o sigilo da Instituição e da respondente.

Certas de contarmos com a sua colaboração, agradecemos e colocamo-nos a disposição para esclarecimentos por meio de telefone (011) 30667544.

Prof ${ }^{a}$ Dr $^{a}$ Kazuko Uchikawa Graziano

Departamento de Enfermagem Médico-Corúrgica

Escola de Enfermagem da USP 


\section{Questionário}

\section{"Utilização das pastilhas de Paraformaldeído"}

Código de identificação da instituição:

1. Quanto à forma de utilização, qual o tempo que os materiais ficam expostos às pastilhas de Paraformaldeído? Assinale a alternativa que mais se aproxima.

() 1 hora () 2 horas () 3 horas () 4 horas () 5 horas () Outros, especifique

2. É utilizada umidade no processo de esterilização com as pastilhas de Paraformaldeído?

() Sim () Não

Em caso afirmativo, assinale como é feita a umidificação do recipiente.

( ) algodão úmido com água destilada

() água destilada em forma líquida

() outros, especifique nas linhas abaixo

3. É realizado algum tipo de cálculo de quantidade de pastilhas de Paraformaldeído conforme o volume do recipiente onde o material é processado?

() Sim () Não

Caso sim, como é realizado esse cálculo?

4. Caso não, a quantidade de pastilhas:

( ) é sempre igual, independente do volume do recipiente;

( ) varia conforme o volume do recipiente, porém a quantidade é calculada leatoriamente;

5. Qual o volume do recipiente mais comumente utilizado?

6. Os artigos esterilizados pelas pastilhas de Paraformaldeído são submetidos ao aquecimento?
( ) Não
() Sim, qual a temperatura?

7. 0 recipiente onde os artigos são processados pelas pastilhas de Paraformaldeído é vedado durante o período de exposição? () Sim. Como? () Não

8. Descreva sucintamente o preparo do material para a esterilização pelas pastilhas de Paraformaldeído quanto a:

a) Limpeza prévia do artigo e do recipiente:

b) Distribuição das pastilhas no recipiente:

c) O artigo é colocado diretamente em contato com as pastilhas de Paraformaldeído?

() Não () Sim, qual a embalagem utilizada?

9. As pastilhas de Paraformaldeído são reutilizadas? () Não () Sim, quantas vezes?

10. Os artigos Processados pelas pastilhas de Paraformaldeído são estocados?
() Sim. Tempo de validade
( ) Não

11. 0 artigo é submetido a algum tratamento após a esterilização, antes do seu uso como artigo estéril?
() Sim. Descreva
() Não

12. Tem notado danos ou alterações no material processado pelas pastilhas?

( )Não ( ) Sim, qual?

13. São realizados testes que comprovam a esterilização dos artigos submetidos às pastilhas de Paraformaldeído?

() Não () Sim, qual o teste?

14. Em relação a toxicidade das pastilhas de Paraformaldeído, que cuidados são dispensados aos funcionários que manuseiam o produto?
() Nenhum
( ) Equipamento de Proteção Individual. Quais?

( )Outros. Quais?

\section{Artigo recebido em 30/01/01}

Artigo aprovado em 05/10/02 